\title{
Extended transthoracic resection compared with limited transhiatal resection for adenocarcinoma of the distal esophagus
}

\author{
Amr Abdel-Naser, MD; Ahmed M Ibrahim, MD; Ahmed M El Fadaly, MD; \\ Osama Fouad, MD; Mohamed Fathy, MD; Mohamed Bahaa, MD; \\ Alaa Abd Allah, $M D$ \\ Department of General Surgery, Ain Shams University
}

\begin{abstract}
There is much controversy about the surgical approach to esophageal carcinoma: should an extensive resection be done to optimize long term survival or should the extent of the operation be limited to obtain lower perioperative morbidity and mortality rates? Thirty-one patients with carcinoma of the lower third of the esophagus who were clinically fit for either transhiatal resection (THR) or transthoracic resection (TTR) were prospectively randomized to THR (16 patients) and TTR (15 patients). Patients of the two groups were comparable in age, sex, preoperative tumor staging, and pulmonary and cardiac risks for surgery. There was no significant difference in the operative complications among both groups. However, the amount of blood loss was significantly more in the TTR group $(P<0.05)$, and the mean operating time was significantly longer in the TTR group $(P<0.00 l)$. There was no difference in postoperative ventilatory requirements, and mean hospital stay between the two groups. There were higher pulmonary complications in the TTR group compared to higher incidence of anastomotic leakage and unilateral vocal cord paralysis in the THR group. However the differences were not statistically significant $(P>0.05)$. There was no 30-day mortality in the THR group but there were 2 mortalities in the TTR group from mediastinitis (1 patients) and pulmonary embolism (1 patient). The median survival rates were 19 and 16.5 months, respectively, for the THR and TTR groups $(P>0.05)$. In conclusion, although there was no demonstrable statistical difference in results between THR and TTR approaches, the THR approach is preferred as early survival rate are better and should be considered for all cases with adenocarcinoma of the lower end of the oesophagus.
\end{abstract}

\section{Introduction:}

Esophageal resection is the only curative therapy for patients with esophageal carcinoma. ${ }^{1}$ Although a variety of retrospective studies had demonstrated improvements in short term outcomes in recent years, changes in long term survival over time are not well established. ${ }^{2}$ Advances in surgical planning, operative technique, and perioperative care had resulted in improved short term outcomes. Experienced centers now reporting, 30-day mortality rates of less than $5 \%$, even with major resections. ${ }^{3}$

For years the procedure of choice for esophageal resection has been the LewisTanner operation, in which the tumor and periesophageal tissue with its adjacent lymph nodes are resected through a right sided thoracotomy in combination with a laparotomy. ${ }^{4}$ In the past decades, two major surgical strategies to improve survival rates had emerged. The first strategy uses radical resection to improve the cure rate, i.e., en block transthoracic resection (including the azygos vein, thoracic duct, overlying pleura, and pericardium). ${ }^{5}$ Alternatively, one could attempt to decrease early postoperative morbidity and mortality rates by limiting the extent of the operation. That outcome might be achieved by a transhiatal resection in which the esophagus is resected through a cervicoabdomianl approach, thus avoiding a formal thoracotomy. 6

The current clinical trial was undertaken to compare the perioperative complications and 2 -years outcomes of limited transhiatal resection (THR) versus extended transthoracic resection (TTR) for patients with carcinoma 
of the lower third of the esophagus to assess the overall value of both techniques.

\section{Patients and methods:}

This study included 31 patients admitted to Ain Shams university hospitals with histologically confirmed adenocarcinoma of the distal esophagus between April 2002 and September 2007. They included 21 males and 10 females; mean age, 56 years (range, 42-69).

The 31 patients were prospectively randomized to two groups:

Group 1: Comprised of 16 patients who underwent transhiatal resection (THR). They included 10 males and 6 females; mean age, 58 years (range, 44-69).

Group 2: Comprised of 15 patients who underwent transthoracic resection (TTR). They included 11 males and 4 females; mean age, 56 years (range, 42-68).

The eligible patients had histologically confirmed adenocarcinoma of the distal esophagus, did not show evidence of distant metastases (including the absence of cytologically confirmed tumor-positive cervical lymph nodes and irresectable celiac lymph nodes), and did not have irresectable local disease.

Patients had to be in adequate physical condition to undergo major surgery (as indicated by their assignment to American Society of Anesthesiologists class I or $\mathrm{II}^{7}$ ). Exclusion criteria were previous or coexisting cancer, previous gastric or esophageal surgery, application of neoadjuvant chemotherapy and/or radiation therapy, and distal extension of the tumor that made it impossible for the surgeon to construct a gastric tube. The preoperative diagnostic work-up consisted of endoscopy with biopsy and histologic examination, thoraco-abdominal CT scan, barium swallow, ultrasonography of the abdomen and neck (with biopsy if indicated), chest radiography, indirect laryngoscopy, and bronchoscopy if tumor ingrowth in the upper airway was suspected.

Table (1): Patients demographics and tumor characteristics.

\begin{tabular}{|l|c|c|c|}
\hline & TTR & THR & P value \\
\hline $\begin{array}{c}\text { Age in years } \\
\text { Mean (range) }\end{array}$ & $58(44-69)$ & $56(42-68)$ & $>0.05$ \\
\hline Sex & \multicolumn{5}{|l|}{} \\
\hline Males & 11 & 10 & $>0.05$ \\
\hline Females & 4 & 6 & $>0.05$ \\
\hline Stage according to the Union Internationale Contre le Cancer 1997 system \\
\hline O/I & 4 & 3 & $>0.05$ \\
\hline II & 3 & 5 & $>0.05$ \\
\hline III & 2 & 1 & $>0.05$ \\
\hline IV & - & - & \\
\hline
\end{tabular}

\section{Operative technique - Transhiatal resection (THR)}

The transhiatal resection (THR) procedure was performed like described by Sugarbaker et al., 8 the esophagus was dissected under direct vision through the widened hiatus of the diaphragm, at least up to the inferior pulmonary vein. The tumor and its adjacent lymph nodes were dissected en bloc. A 3-cm-wide gastric tube was constructed. The left gastric artery was transected at its origin, with resection of local lymph nodes. Celiac lymph nodes were dissected only when there was clinical suspicion of involvement. After right-sided mobilization of the cervical esophagus, the intrathoracic, normal esophagus was bluntly resected from the neck to the abdomen with use of a vein stripper. Esophagogastrostomy was performed in the neck, without cervical lymphadenectomy. Figures(1-9) illustrate the technique 


\section{Operative technique - Transthoracic resection (TTR)}

The transhiatal resection (THR) procedure was performed like described by Sugarbaker et al., 8 posterolateral thoracotomy was the first step in transthoracic resection with extended en bloc lymphadenectomy. The thoracic duct, azygos vein, ipsilateral pleura, and all periesophageal tissue in the posterior mediastinum were dissected en bloc. The specimen included the lower and middle mediastinal, subcarinal, and right-sided paratracheal lymph nodes (dissected en bloc). The aortapulmonary-window nodes were dissected separately. Through a midline laparotomy, the paracardial, lesser curvature, left-gastric-artery (along with lesser curvature), celiac trunk, common-hepatic-artery, and splenic-artery nodes were dissected, and a gastric tube was constructed. The cervical phase of the transthoracic procedure was identical to the transhiatal procedure, but a left sided approach was used. ${ }^{5}$ In both procedures, the origin of the left gastric artery was marked. Subcarinal nodes were marked separately in case of a planned transthoracic resection.

The resection specimen was carefully palpated for the presence of lymph nodes and subsequently dissected. All lymph nodes identified by the pathologist were collected in separate boxes and marked according to location, then cut into 2 with both sides stained with hematoxylin and eosin. Tumors were assigned pathologic tumor-node-metastasis stages according to the Union Internationale Contre le Cancer 1997 system. ${ }^{9,10}$

Operative and postoperative data were collected prospectively. The main outcome measures were postoperative complications, mortality, and, survival. Operating time was measured from skin incision to completion of wound closure. Hospital stay was measured from the date of operation to the date of discharge. Hospital mortality was defined as death within the same hospital admission for surgery. Survival was measured from the date of operation.
All continuous values were expressed as mean \pm SE of mean unless otherwise stated. Univariate analysis was performed by MannWhimey U test for continuous variables and by chi-square test (with Yates' correction when appropriate) for categorical variables.. Statistical analysis was performed with standardized biomedical statistical software (SPSS/PC+, SPSS, Chicago, Illinois). Statistical significance was taken when $\mathrm{P}<0.05$.

\section{Results:}

A total of 31 patients with adenocarcinoma of the distal esophagus were randomly assigned to limited THR or to extended TTR with en bloc lymphadenectomy. Patients of the two groups were comparable in age, gender, preoperative tumor staging, and pulmonary and cardiac risks for surgery.

Operative complications are given in Table(2). There were no important differences between TTR and THR except for the amount of blood loss which was higher in the TTR group and the duration of surgery which was longer in the TTR group.

Post-operative complications were tabulated in Table(3). Higher rate of pulmonary complications were recorded in the TTR group but anastomotic leak and vocal cord paralysis were more frequent after THR resections.

ICU and hospital stay were longer in the TTR group when compared to the THR group. There was no mortality in the THR but 2 patients died in the TTR group, one from mediastinitis and the other from pulmonary embolism.

Table(2) shows the operative complications and Table(3) mentions the perioperative morbidity and mortality. 
Table (2): Operative complications.

\begin{tabular}{|l|c|c|c|}
\hline Operative complications & TTR & THR & P value \\
\hline Tracheo-bronchial tear & - & - & \\
\hline Significant bleeding & 2 & 1 & $>0.05$ \\
\hline Blood loss & $1500 \mathrm{ml}$ & $900 \mathrm{ml}$ & $<0.05$ \\
\hline Operative time & 305 & 210 & $<0.001$ \\
\hline
\end{tabular}

Table (3): Postoperative complications, hospital stay and 30-day mortality.

\begin{tabular}{|l|c|c|}
\hline & TTR & THR \\
\hline Cardiac complications & & \\
\hline Pulmonary complications & 9 & 4 \\
\hline Anastomotic leak & 1 & 1 \\
\hline Vocal cord paralysis & - & - \\
\hline Chylous leakage & - & 2 \\
\hline Wound infection & 4 & 3 \\
\hline ICU stay (days) & 7 & 14 \\
\hline Hospital stay & 17 & - \\
\hline 30-day mortality & 2 & 3 \\
\hline
\end{tabular}
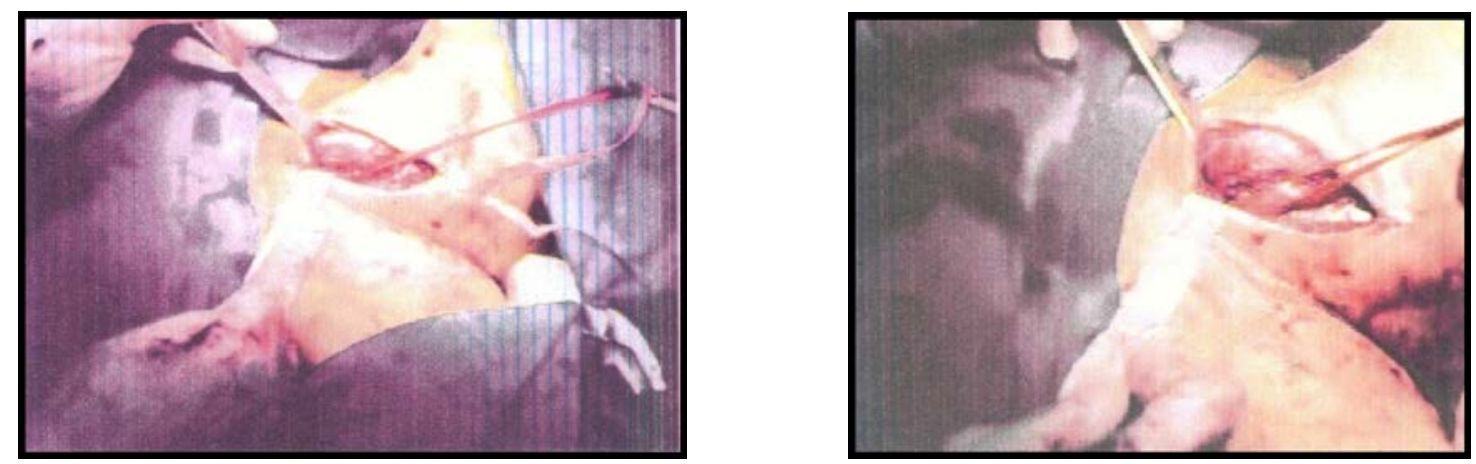

Figure (1): A and B Cervical incision and tape around the esophagus.

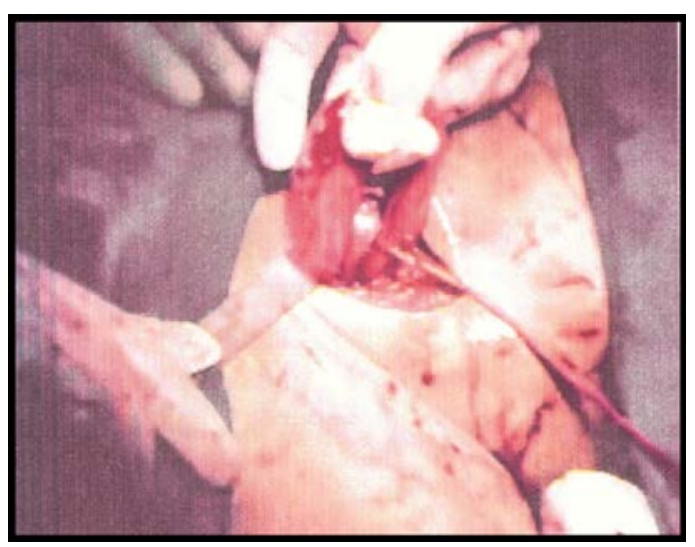

Figure (2): Delivery of the esophagus.

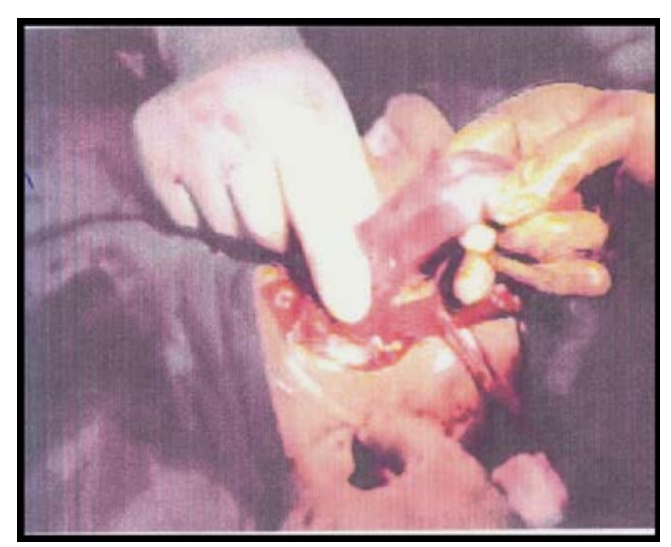

Figure (3): Palpation of the mass at lower end of esophagus. 

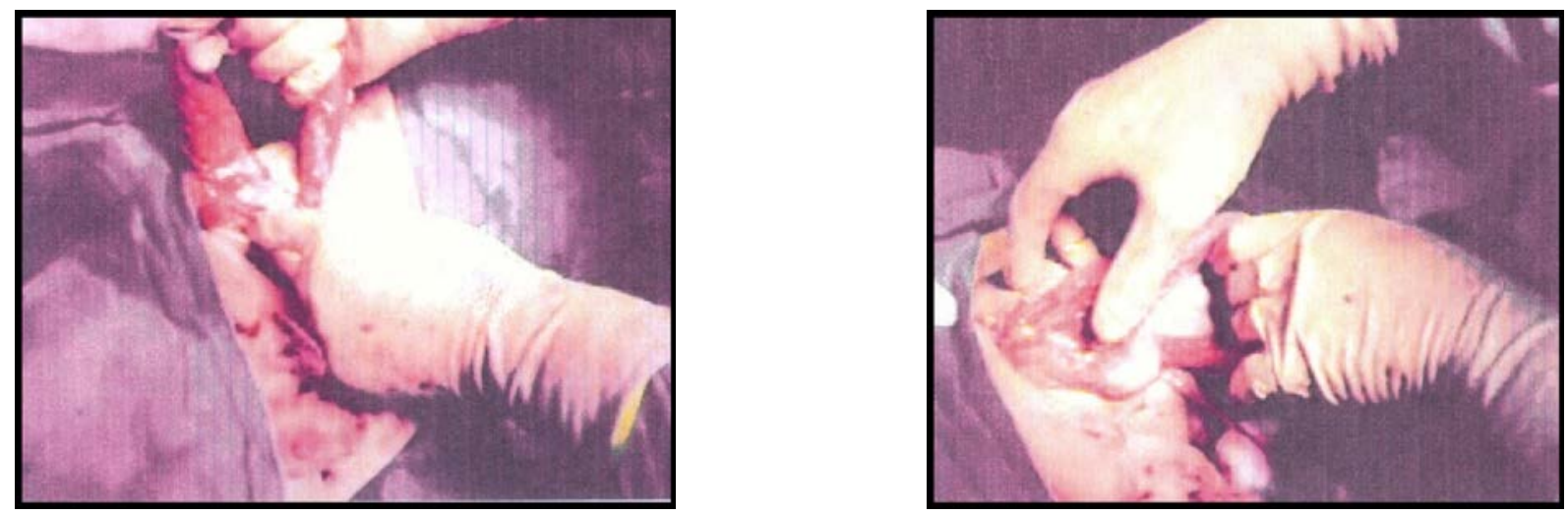

Figure (4): A and B Delivery of the fundus of the stomach.
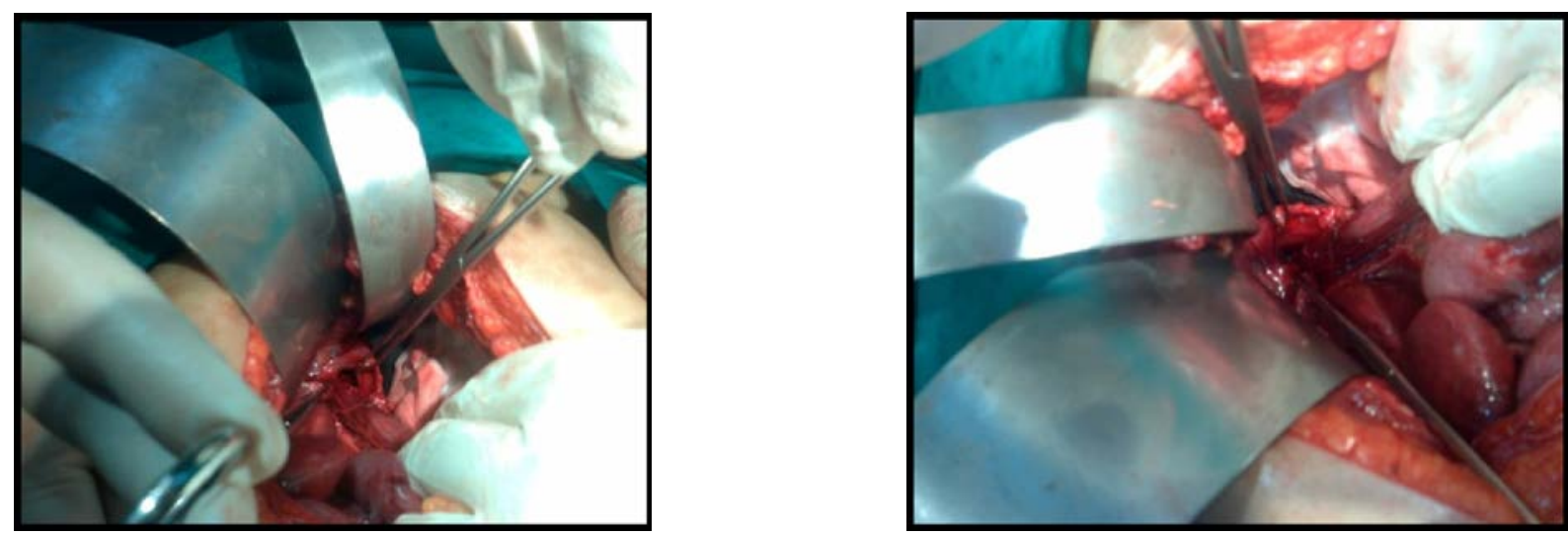

Figure (5): $A$ and B Widening of the hiatus.
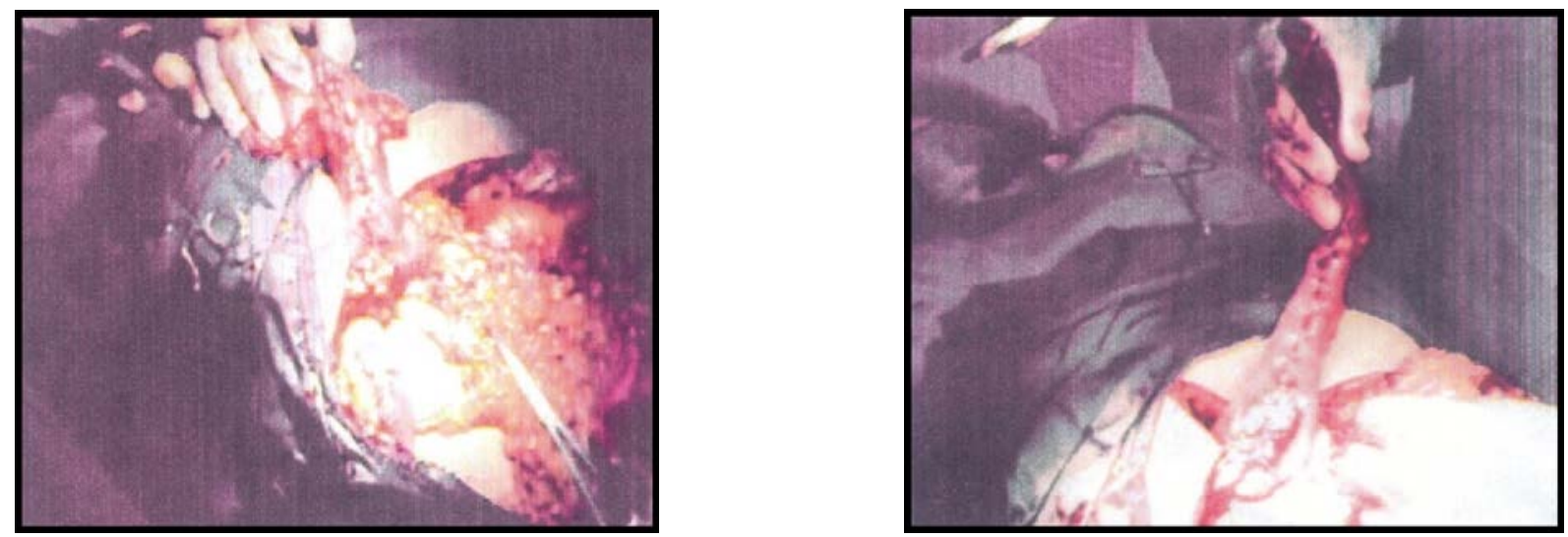

Figure (6): A and B Fashioning of the gastric tube.
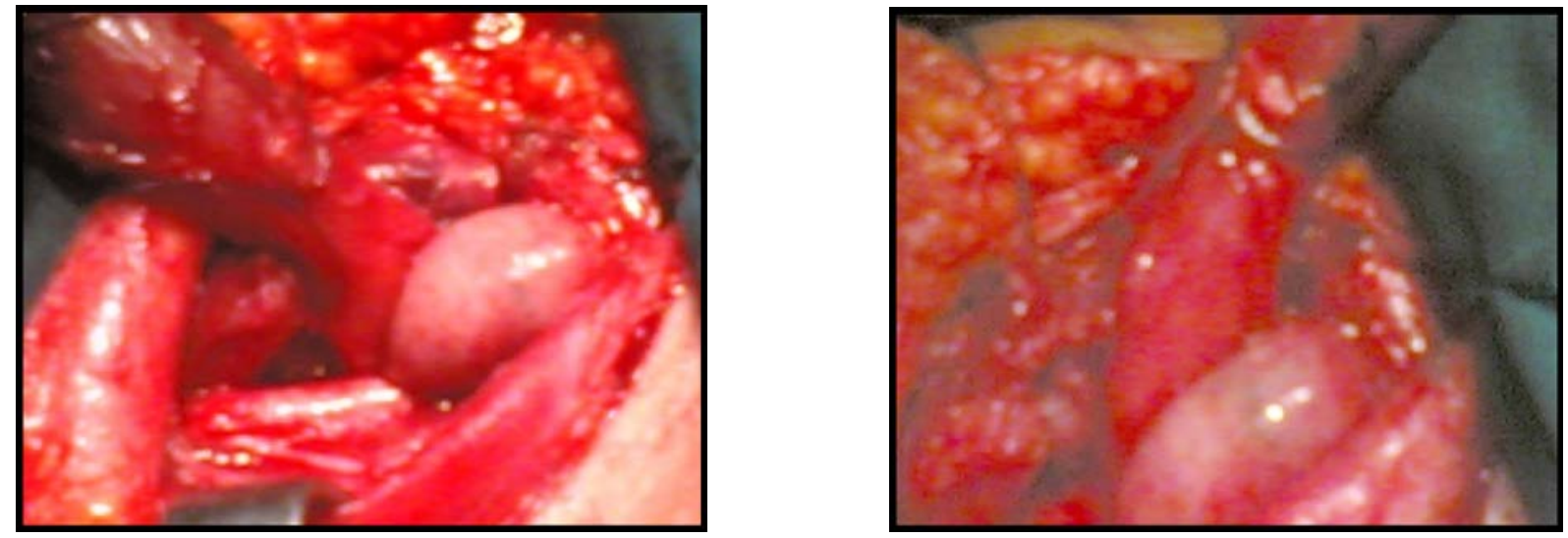

Figure (7): A and B Preparing for anastomosis in the neck. 


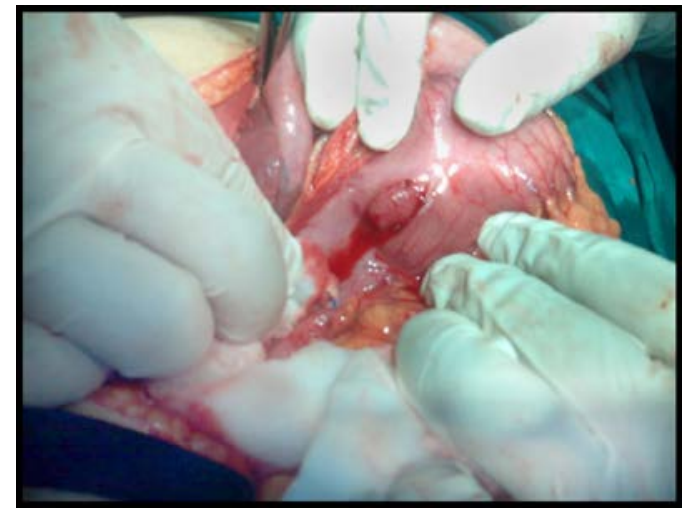

Figure (8): Pyloromyotomy.

In all patients, the operation was performed at least 2 years earlier, ensuring a minimal potential follow-up of 2 years (range 2-4.4 years). During follow-up, 17 patients (54.8\%) had deceased; 2 patients $(6.5 \%)$ died in-hospital because of postoperative complications Table(4). Overall 2-year survival was comparable between patients after transhiatal resection $(50 \%)$ and patients after transthoracic resection (40\%, P > 0.05) Figure(10).

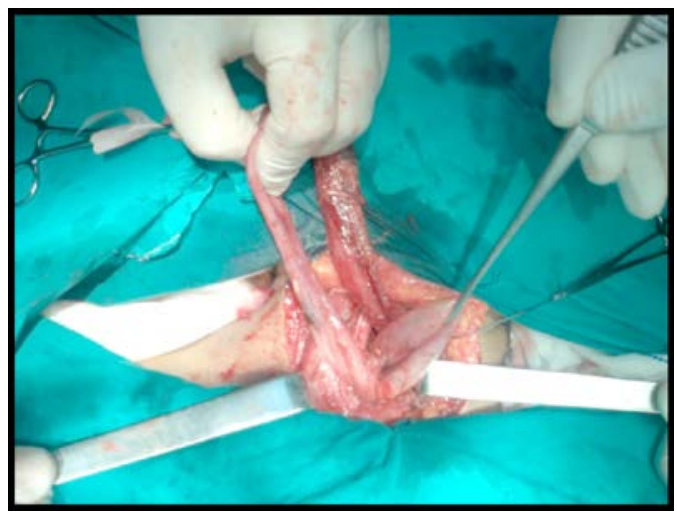

Figure (9): Delivery of the esophagus.

11 patients of the THR group and 9 patients of the TTR group have developed recurrence $(\mathrm{P}>0.05)$. The sites of recurrence were similar in the two groups. The time to develop recurrence in the two groups of patients was not different statistically. Two patients of THR group developed benign anastomotic strictures that required endoscopic dilatation. The median survival rates were 19 and 16.5 months, respectively, for the THR and TTR groups ( $\mathrm{P}$ $>0.05)$.

Table (4): Follow-up at 2 years of 31 patients who underwent resection after randomization to either transhiatal esophagectomy or transthoracic esophagectomy.

\begin{tabular}{|l|c|c|c|c|c|}
\hline Status at the last follow-up & \multicolumn{2}{|c|}{$\begin{array}{c}\text { TTR } \\
(\mathrm{n}=15)\end{array}$} & \multicolumn{2}{c|}{$\begin{array}{c}\text { THR } \\
(\mathrm{n}=16)\end{array}$} & P value \\
\hline & Patients & Percent & Patients & Percent & \\
\hline Alive & 6 & 40 & 8 & 50 & $>0.05$ \\
\hline Deceased & 9 & 60 & 8 & 50 & $>0.05$ \\
\hline Without recurrence & 6 & 40 & 5 & 31.25 & $>0.05$ \\
\hline With recurrence & 2 & 13.3 & 4 & 25 & $>0.05$ \\
\hline Locoregional & 6 & 40 & 5 & 31.25 & $>0.05$ \\
\hline Distant & 1 & 6.7 & 2 & 12.5 & $>0.05$ \\
\hline Both & & & & & \\
\hline
\end{tabular}




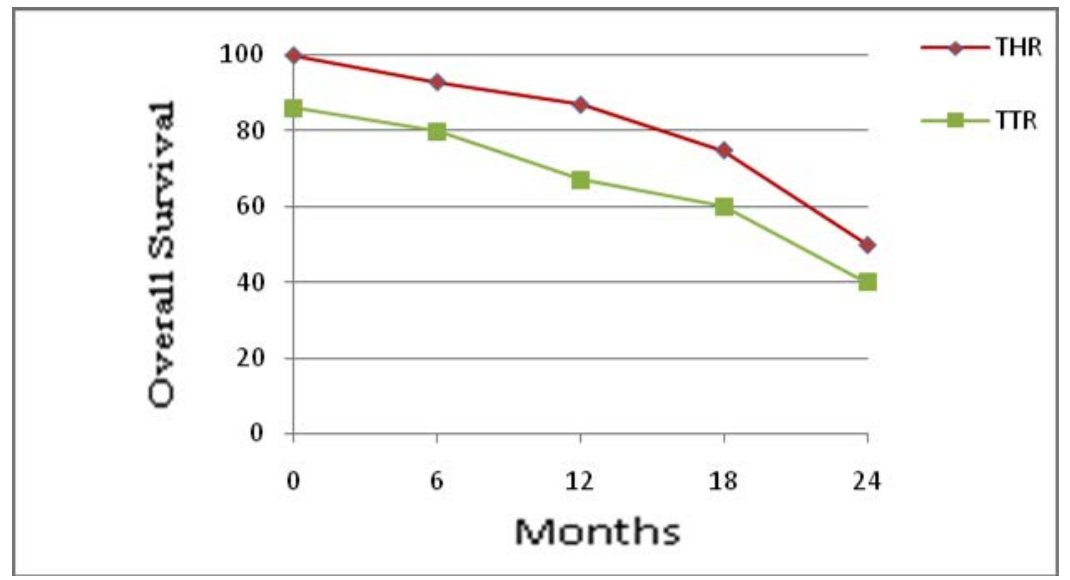

Figure (10): Overall survival of all patients after transhiatal (red line) or transthoracic (green line) esophagectomy $(P>0.05)$.

\section{Discussion:}

There has been much debate about the optimal type of resection for esophageal cancer namely adenocarcinoma. ${ }^{11-14}$ The less aggressive surgical approach, for adenocarcinoma of the esophagus namely the transhiatal approach is justified by findings derived from studies investigating the spread of lymph nodes in cases of adenocarcinoma, allowing to conclude that the lymph node metastases associated with distal adenocarcinomas are initially seen to metastasize into the lymph nodes in the vicinity of the tumour and only later into the lymph nodes of the upper mediastinal region. ${ }^{15,16}$

Recent analysis did not demonstrate a relevant difference in survival for patients with $\mathrm{N} 0$ and N1 stages undergoing transhiatal or transthoracic esophagectomy for adenocarcinoma. ${ }^{3}$ It is questionable and has statistically not proved significant in a prospective randomized study by Hulscher et al. ${ }^{6}$ if an extensive mediastinal lymph node dissection in addition to the clearance of abdominal lymph nodes offers any prognostic advantages in adenocarcinoma of the esophagus considering the increased morbidity associated with the transthoracic approach.

When comparing the perioperative complications between transthoracic and transhiatal procedures. There was a low risk of injury to the major airways or major haemorrhage during transhiatal resections. In the study of Gockel et al., 3 blood loss was greater after transthoracic resections, and in their study, blood loss was even doubled in the transthoracic resection group. The operative time was longer for the transthoracic resections and this was also apparent in the results of the present study.

Theoretically, transthoracic resections have the disadvantages of a formal thoracotomy, which might result in a higher number of pulmonary complications. This was confirmed by the present data and this also might explain the prolonged stay in ICU in this group as reported by Hulscher et al., ${ }^{6}$ and Chu et al., ${ }^{17}$ and confirmed by the present study.

For thoracic resections, the anastomosis can be made cervically, but often it is made in the chest. ${ }^{5}$ During transhiatal procedures, the anastomosis is always made in the neck. ${ }^{8} \mathrm{~A}$ cervical anastomosis carries a higher risk of leakage than an intrathoracic anastomosis, but the risk of (highly lethal) mediastinitis diminishes when leakage occurs. ${ }^{18-20}$ However, most cervical leakages are subclinical, i.e., only seen radiologically, and do not require surgical exploration because they resolve spontaneously 10 to 35 days postoperatively. When surgical drainage is required, opening the cervical incision almost always provides sufficient drainage $6,20-22$ and this matches with the results of the present study where 3 patients in the transhiatal group developed anastomotic leak which resolved spontaneously in contrast to the single case who had leak in the transthoracic approach but died from mediastinitis.

Vocal cord paralysis from recurrent laryngeal nerve injury was reported only in trashiatal resections in the present study and 
this differs from others results, ${ }^{23-25}$ who reported injury after both approaches. This might be explained by the fact that in their study there was cervical dissection and the anastomosis was constructed in the neck with the transthoracic approach in some cases.

Twenty years ago the average hospital mortality rate after resection of esophageal carcinoma was $29 \% .{ }^{25}$ Ten years later the resection mortality rate was more than halved to $13 \% .{ }^{26}$ Today, the average hospital mortality rate is almost halved again: when all data were combined the hospital mortality rate was $7.5 \%$. Mortality rates varied widely $(0 \%$ to $27.8 \%)$ and decreased with increasing the experience and a higher hospital volume. In experienced centers, hospital mortality rates should be below $5 \% .^{27}$

30 day in-hospital mortality rate was higher after transthoracic resections; despite that many surgeons perform transhiatal resections on older patients with more comorbidity. This finding was confirmed by Rindani and coworkers, ${ }^{28}$ who reviewed the literature from 1986 to 1996 and found the mortality rates, 9.5\% for Lewis-Tanner resections compared with $6.3 \%$ for transhiatal resections and this differs with the results of this study, where there was 2 mortalities in the TTR group with no mortality in the THR group and this might be attributed to the small number of patient in the present study.

During follow up, the three patients that developed anastomotic leakage from the THR group developed stricture that required only a single dilatation but none from the TTR developed anastomotic stricture.

The reason for the anastomotic leak is attributed to insufficient blood flow at the distal end of the gastric tube. ${ }^{29}$ Kawai et al. ${ }^{30}$ described a technique to improve the vascularity of the gastric tube by anastomosing the short gastric vessels end to end with the recipient vessels available at the neck.

In this study, we demonstrate that there is no significant 2 years overall survival benefit for either approach, Results of nonrandomized and retrospective studies had been controversial in this respect. ${ }^{18-20,31}$ Patients with carcinoma of the lower third of the esophagus had a $40 \%$ overall 2-year survival benefit if operated via the extended transthoracic approach, in comparison to 50\% 2-year overall survival if operated via the limited transhiatal approach. These findings are in line with those recently published by Sasako et al., ${ }^{14}$ In a randomized trial, they compared the extended left thoracoabdominal approach with the limited transhiatal approach for cancer of the lower third esophagus. Also in that study, no survival difference was found with either approach.

The advantage of the TTR approach is to allow a more complete clearance of involved lymph nodes and, theoretically, provide a better chance for long disease free survival. However, the present prospective randomized study revealed no difference in the occurrence and the sites of recurrence as well as survival between the two groups. Randomized study by Goldminc et al ${ }^{32}$ also demonstrated similar disease free survival between the two approaches irrespective of the lymph node status.

In conclusion, survival rates after THR is equivalent to or better than that seem after TTR and hence transhiatal esophagectomy should be considered in all patients requiring esophagectomy for benign or malignant disease, even adenocarcinoma of the lower end of the esophagus.

\section{References:}

1- Wong J: Transhiatal oesophagectomy for carcinoma of the thoracic oesophagus. $\mathrm{Br}$ J Surg 1986; 73: 89-90.

2- Swanson SJ, Batirel HF, Sugarbaker DJ, et al: Transthoracic esophagectomy with radical mediastinal and abdominal lymph node dissection and cervical esophagogastrostomy for esophageal carcinoma. Ann Thorac Surg 2001; 72: 1918- 1925.

3- Gockel I, Heckhoff S, Messow CM, Kneist $\mathrm{W}$, Junginger $\mathrm{T}$ : Transhiatal and transthoracic resection in adenocarcinoma of the esophagus: Does the operative approach have an influence on the long term prognosis? World J Surg Oncol 2005; 3: 40.

4- McKeown K: Total three-stage oesophagectomy for cancer of the oesophagus. Br J Surg 1976; 63: 259. 
5- Swanson S, Grondin S, Sugarbaker D: Total esophagectomy: The brigham and women's hospital approach. Operative Techniques in Thoracic and Cardiovascular Surgery: A Comparative Atlas 1999; 4: 197.

6- Hulscher BF, Tijssen GP, Obertop H and Lanschot JB: Transthoracic versus transhiatal resection for carcinoma of the esophagus: A meta analysis. Ann Thorac Surg 2001; 72: 306-313.

7- ASA physical status classification system. Park Ridge III.; American Society of Anesthesiologists, 2002. Available at: http://www.asahq.org/clinical

8- Sugarbaker DJ, DeCamp MM, Liptay MJ: Procedures to resect and replace the esophagus. In: Zinner MJ, Schwartz SI, Ellis H (eds): Maingot's Abdominal Operations, 12th ed. Stanford, Appleton \& Lange, 1997, p 885

9- Sobin LH, Wittekind C: TNM Classifications of malignant tumours. New York: John Wiley \& Sons; 2003.

10-Steup WH, De Leyn P, Deneffe G, et al: Tumors of the esophagogastric junction. Long-term survival in relation to the pattern of lymph node metastasis and a critical analysis of the accuracy or inaccuracy of pTNM classification. $J$ Thorac Cardiovasc Surg 2005; 119: 85-94.

11-Siewert RJ, Feith M, Werner M, et al: Adenocarcinoma of the esophagogastric junction: results of surgical therapy based on anatomical/topographic classification in 1,002 consecutive patients. Ann Surg 2000; 232: 353-361.

12-Orringer M, Stirling M: Transhiatal esophagectomy for benign and malignant disease. J Thorac Cardiovasc Surg 1993; 105: 265.

13-Ellis FH, Gibb SP, Watkins E Jr: Esophagogastrectomy: A safe, widely applicable, and expeditious form of palliation for patients with carcinoma of the esophagus and cardia. Ann Surg 1983; 198: 531.

14-Sasako M, Sano T, Yamamoto S, et al: Left thoracoabdominal approach versus abdominal-transhiatal approach for gastric cancer of the cardia or subcardia: A randomised controlled trial. Lancet Oncol.
2006; 7: 644-651.

15-Tachimori Y, Kato H, Watanabe H, Sasako M, Kinoshita T, Maruyama K: Difference between carcinoma of the lower esophagus and the cardia. World J Surg 1996; 20: 507-510.

16-Tytgat GN, BArtelink H, Bernards R, et al.: Cancer of the esophagus and gastric cardia: recent advances. Dis Esophagus 2004; 17: 10-26.

17-Chu KM, Law SY, Fok M, et al: A prospective randomized comparison of transhiatal and transthoracic resection for lower-third esophageal carcinoma. Am J Surg 1997; 174: 320-324.

18 -Krasna M: Left transthoracic esophagectomy. Chest Surg Clin N Am 1995; 53: 543.

19-Goldminc M, Maddern G, Le Prise E, et al: Oesophagectomy by a transhiatal approach or thoracotomy: A prospective randomized trial. Br J Surg 1993; 80: 367370.

20-Gluch L, Smith RC, Bambach CP, Brown AR: Comparison of outcomes following transhiatal or Ivor Lewis esophageactomy for esophageal carcinoma. World J Surg 1999; 23: 271-276.

21-Moon MR, Schulte WJ, Haasler GB, Condon RE: Transhiatal and transthoracic esophagectomy for adenocarcinoma of the esophagus. Arch Surg 1992; 127: 951-5.

22-Jauch KW, Bacha EA, Denecke H, Anthuber M, Schildberg FW: Esophageal carcinoma: Prognostic features and comparison between blunt transhiatal dissection and transthoracic resection. Eur J Surg Oncol 1992; 18: 553-62.

23-Hulscher JBF, Van Sandick JW, De Vriese PP, Van Lanschot JJB, Obertop H: Vocal cord paralysis after subtotal oesophagectomy. Br J Surg 1999; 86: 1583-1587.

24-McLarty AJ, Deschamps C, Trastek VF, Allen MS, Pairolero PC, Harmsen WS: Esophageal resection for cancer of the esophagus: Long term function and quality of life. Ann Thorac Surg 1997; 63: 15681572 .

25-Iannettoni MD, Whyte RI, Orringer MB: Catastrophic complications of the cervical 
esophagogastric anastomosis. I Thorac Cardiovasc Surg 1995; 110: 1493-1501. 26-Jamieson GG, Mathew G, Ludemann R, Wayman J, Myers JC, Devitt PG: Postoperative mortality following oesophagectomy and problems in reporting its rate. Br J Surg 2004; 91: 943-947.

27-Gockel I, Sultanov FS, Domeyer M, Gonner $\mathrm{U}$ and Junginger TH: Developments in esophageal surgery for adenocarcinoma: a comparison of two decades. BMC Cancer 2007; 7 : 114.

28-Rindani R, Martin CJ, Cox MR: Transhiatal versus Ivor Lewis oesophagectomy: Is there a difference? Aust N Z J Surg 1999; 69: 187-194.

29-Briel JW, Tamhankar AP, Hagen JA et al.: Prevalence and risk factors for ischemia, leak, and stricture of esophageal anastomosis: Gastric Pull-up versus colon interposition. J Am Coll Surg 2004; 198 (4): S 36-541.
30-Kawai K, Kakibuchi M, Sakagami M et al: Supercharged gastric tube pull up procedure for total esophageal reconstruction. Ann Plast Surg 2001; 47: 390-393.

31-Wong J: Surgery in esophageal cancer: How radical should it be. Dig Surg 1993; 10: 164-166.

32-Goldminc M, Maddern G, Le-Prise E, et al.: Oesophagectomy by a transhiatal approach or thoracotomy: A prospective randomized trial. Br J Surg 1993; 80: 367370. 